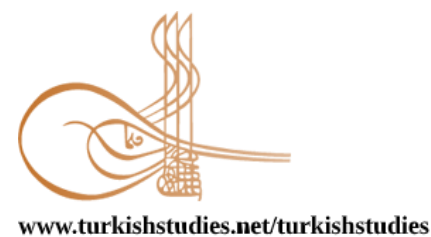

Turkish Studies

eISSN: $1308-2140$

Research Article / Araștırma Makalesi

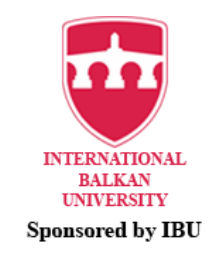

\title{
14. Yüzyıl Osmanlı Beyliği’nin Gizli Tanıkları: Arkeolojik ve Mimari Miras
}

Secret Evidences of the 14th Century Ottoman History: Archaeological And Architectural Heritage

\author{
Hasan Yılmazyaşar*
}

\begin{abstract}
The founding period of the Ottoman Principality has been the subject of many scientific publications. However, our knowledge of not only the history of this period, but also many facts such as culture, art, architecture, economy and institutional structure is extremely limited. There are still many divergent opinions as to the origins of the Ottomans and the date in which the Beylik was first founded. Most of what is known about the 14th century of the Ottoman Principality consists of the data in the Ottoman chronicles written after the second half of the 15th century. In this context, the existence of disjointed and incomplete information in modern historical studies and the existence of different views and thoughts on many issues are better understood. Another important problem is the inadequacy of alternative field studies and the ignoring of existing studies due to the lack of interdisciplinary collaboration. This being the case, the main purpose of this article is to emphasize the vitality of the archaeological and architectural data concerning the socio-cultural structure of the early Ottoman period. For this purpose, the reason why the Ottoman archaeology is indispensable for researchers of the Ottoman period will be explained through important historical examples. Another important source of information is the Ottoman architectural works. If read properly and correctly, architectural works/remains provide content that is a document for many scientists, especially archaeologists, art historians, architects and historians. In this article, architectural data will be evaluated in the context of cultural interaction and social cultural structure.
\end{abstract}

Structured Abstract: The founding period of the Ottoman Beylik has always drawn attention of historians specialized in the Ottoman history. However, unexplored parts of the period in terms of the socio-cultural environment, economy, administrative organization and institutional structure of the Ottoman Empire outweigh the data collected to date. There are still many divergent opinions as to the origins of the Ottomans and the date in which the Beylik was first founded. Moreover, these divergent opinions are almost always mutually exclusive, which has eventually contributed to the chaotic and unstable set of data about the period. The fact that there are no historical chronicles dating back to the 14th century, and that those which can be classified as historical documents are merely a few inscriptions, some endowment-charters (vakfiye) and a handful of coins poses a considerably obstacle for researchers. In addition, the Byzantine chronicles meant to provide due evidence to the gaps in question fall short of presenting sufficient amount of data to profoundly address the problem.

This being the case, the main purpose of this article is to emphasize the vitality of the archaeological and architectural data concerning the socio-cultural structure of the early Ottoman period. For this purpose,

\footnotetext{
${ }^{*}$ Dr. Öğr. Üyesi, Anadolu Üniversitesi, Edebiyat Fakültesi, Sanat Tarihi Bölümü. Asst. Prof. Anadolu University, Faculty of Humanities, Department of Art History. 
the reason why the Ottoman archaeology is indispensable for researchers of the Ottoman period will be explained through important historical examples. Comprehensive archaeological excavations in early Ottoman period settlements such as Karacahisar, Bilecik, Yenişehir, Bursa, Yalova, İnegöl and İznik will be able to provide new data on many subjects related to the Ottoman Empire, especially the establishment period, which we focus on in this article. Unfortunately, it is not possible to say that enough archaeological studies have been carried out in areas with the potential to reach the mentioned data. Although there has been an interest in this field in Turkey in recent years, Ottoman archeology is still in the process of formation. To emphasize at this point is the fact that findings derived from art history researches are not sufficiently referenced in historical research, and vice versa. Perhaps the fundamental reason behind this case is the absence of joint research collaboration to be carried out amongst these disciplines. Another important lack, in this regard, concerns the numerical distribution of archaeological research carried out in Turkey.

Unfortunately, such studies are not as many as it should be. According to a recent report by Turkish Ministry of Culture, there have been around 145 excavations annually approved by the ministry between 2006 and 2020. However, merely 7,27 \% (2006: 110/8) and 9,35\% (2020: 139/13) of these excavations were conducted on Turkish-Islamic periods. The number of excavations directly related to the early Ottoman period is only 3: Excavation of Tile Furnaces in Iznik, Excavation of Karacahisar Castle in Eskisehir and Excavation of Edirne Palace. There are numerous excavations in the sites that were home to the Palaeolithic, Neolithic, Chalcolithic, Bronze Age, Iron Age, Antiquity and the Byzantine periods in Turkey and these are carried out uninterruptedly and complementarily. This data largely reveals that it is not the quantity of archaeological research but the significance attributed to the Turkish - Islam and the Ottoman archaeology that is rather problematic and below the required level. One of the main reasons for this is the insufficient number of specialists dealing with the Ottoman archaeology at the universities in Turkey. That being the case, the field falls short of drawing academic interest.

Another important source of information is the Ottoman architectural works. If read properly and correctly, architectural remains are highly important for archaeologists, architects and art historians alike. Architectural data will be approached in the context of cultural interactions and social structures in this article. It is unfortunate that the architectural traditions that had an impact on formation of the Ottoman Architecture still remain to be examined. The main reason for this is the fact that art history and architectural history studies mostly focus on documentation. Despite the new data contributed to literature by such studies, critical shortcomings in the analytical evaluation process of the data in question in terms of historical, geographical, political, military, commercial and social effects are still prevalent today. Architectural works of art are not independent of these factors at all; contrarily, they are inevitably shaped by all the dynamics within a society and embody these dynamics to a considerable degree.

In summary, academic studies and excavations on the Ottoman art and architecture can potentially address the problem of inadequacy of written documents and supply the researchers with due means to fill in gaps in the field, hence illuminating the historical process. In a sense, they are the secret witnesses of the period. Approaching the study on the Ottoman art and architecture with a relatively more analytical and theoretical viewpoint, and giving due importance to the Ottoman archaeology will eventually enable scholars working on the period to be well-equipped in terms of acquiring solid data while carrying out their research.

Keywords: Art History, Ottoman, 14. century, history, architecture, archeology, cultural heritage

Öz: Osmanlı Beyliği’nin kuruluş dönemi çok sayıda bilimsel yayına konu olmasına karşın bu dönemin sadece tarihi değil, kültür, sanat, mimari, ekonomi, kurumsal yapı gibi bir çok olgusuna dair bilgilerimiz son derece sınırlıdır. Osmanlıların kökenleri ve Beyliğin kurulduğu tarih konusunda bile hâlâ birçok farklı görüş bulunmaktadır. Osmanlı Beyliği'nin 14. yüzyılına dair bilinenlerin büyük bir kısmı 15. yüzyılın ikinci yarısından sonra yazılmış Osmanlı kroniklerinde yer alan verilerden oluşmaktadır. Bu bağlamda modern tarih araştırmalarındaki birbirinden kopuk, bütünlüğü olmayan bilgiler ile birçok hususta farklı görüş ve düşüncelerin varlığı daha iyi anlaşılmaktadır. Bu ortamda alternatif alan çalışmaların yeterli düzeyde olmayışı, var olan çalışmalarının ise disiplinler arası ortak çalışma eksikliği sebebi ile göz ardı edilmesi önemli bir diğer sorundur. Bu makalenin temel amacı, erken Osmanlı döneminin sosyo-kültürel yapısına ilişkin arkeolojik ve mimari verilerin önemini vurgulamaktır. Bu amaçla Osmanlı Arkeolojisi’nin Osmanlı araştırmaları açısından önemini dönem tarihinin öne çıkan tarihsel olay-olguları örneklenerek tartışılmaya çalışılacaktır. Döneme dair bir diğer önemli veri / bilgi kaynağı da Osmanlı mimari eserleridir. Düzgün ve 
doğru okunursa, mimari eserler / kalıntılar arkeologlar, sanat tarihçileri, mimarlar ve tarih uzmanları başta olmak üzere bir çok bilim insanı için birer belge niteliğinde içerik sunmaktadır. Bu makalede, mimari veriler kültürel etkileşim ve sosyal kültürel yapı bağlamında ele alınarak değerlendirilecektir.

Anahtar Kelimeler: Sanat Tarihi, Osmanlı, 14. yüzyıl, tarih, mimari, arkeoloji, kültürel miras

\section{Yüzyıl Osmanlı Beyliği'nin Gizli Tanıkları: Arkeolojik ve Mimari Miras}

Osmanlı Beyliği'nin kuruluş dönemi Osmanlı tarihinde uzmanlaşmış tarihçiler tarafından sıklıkla konu edinilen ve çok sayıda yayınla tanıtılan bir süreç olmasına karşın, kuruluş döneminin de içerisinde olduğu 14. yüzyıl Osmanlı Beyliği'nin tarihi ile birlikte, sosyo kültürel ortamı, ekonomisi, yönetim organizasyonu, kurumsal yapısına dair bilinmeyenler bilinenlerden fazladır. Öyle ki halen Osmanlıların kökeni ${ }^{1}$ ve beyliğin kuruluş tarihi ${ }^{2}$ bile tarihçileri en fazla meşgul eden ve farklı öneriler ile devam eden sorunsallar olarak tartışılmaktadır. Bu belirsizlikler C. İmber (1993, s. 75)'in Osmanlı tarihinin kuruluş sürecini bir kara delik olarak tanımlamasına ve söz konusu boşluğu doldurmaya yönelik her türlü girişimin imkansızlığına işaret eden bir sonuca ulaşmasına sebep olmuştur ${ }^{3}$. Alandaki her araştırmacı için kaynakların ve arşiv belgelerinin tutarlı bir literatür oluşturmaya yetmediği açık olsa da son yıllarda Osmanlı Beyliği'nin kuruluş dönemini konu alan çok sayıdaki çalışmada yeni bakış açıları ile döneme dair bazı bilinmeyenlere 1şık tutan sonuçlara ulaşılması, bu alanda yeni araştırmalara duyulan ihtiyacı ortaya koymuştur. Ancak 14. yüzyıldan günümüze ulaşan herhangi bir tarihsel kroniğin bulunmayış ${ }^{4}$, dönem belgesi olarak değerlendirilebilecek kaynakların, az sayıda kitabe ${ }^{5}$ ile birkaç vakfiye ${ }^{6}$ ve yine az sayıda sikkeden ${ }^{7}$ ibaret olması araştırmacıların karşısında duran en büyük engeldir. Bu hususta bazı sorunsallara yanıt olması beklenen Bizans kronikleri de bahsi geçen boşluğu dolduracak nitelikte yeterli veri sunmamaktadir. $^{8}$

Osmanlı Beyliği'nin 14. yüzyılına dair bilinenlerin büyük bir kısmı 15. yüzyılın ikinci yarısından sonra yazılmış Osmanlı kroniklerinde yer alan verilerden oluşmaktadır. Anonim Tevarih ile Aşı1kpaşazâde Tarihi, Kitabı Cihannüma ve Oruç Bey Tarihi'nin temsil ettiği 15. yüzyıl Osmanlı kroniklerindeki kuruluş dönemine dair bilgiler, yazarların aynı kaynağı (Yahşi Fakih'in

\footnotetext{
${ }^{1}$ Osmanlının kökeni ve kuruluş tarihi öncelikle H. Gibbons, F. Köprülü, P. Wittek, F. Giese ve H. İnalcık olmak üzere günümüze kadar birçok araştırmacı tarafından konu edilmiştir. Söz konusu tartışmalara dair tüm yayınları konu kapsamında tanıtmak mümkün olmamakla birlikte Osmanlı'nın kuruluş sürecine dair dair geçmiş çalışmaları da analitik bir gözlemle irdeleyen son dönem yayınları için bkz. (Kafadar 2010; Lowry, 2010; Emecen, 2012).

2 Bugüne kadar birçok araştırmada Osmanlı Beyliği'nin kuruluş tarihi Osmanlı kroniklerinde yer alan bilgiler doğrultusunda Karacahisar'ın fethi sonrasında ilk hutbenin okunduğu tarih olan 1299 yılı olarak benimsenmiştir. Son dönemde başta Halil İnalcık olmak üzere söz konusu tarih üzerindeki çekinceler ve Bafeus Savaşı merkezli Pachimeres refreransı ile 1302 yılının Osmanlı'nın kuruluş tarihi olarak kabul edilmesi yönünde görüşler ileri sürülmüştür. Detaylı bilgi ve tartışmalar için bkz. (İnalcık, 2010).

3 "Çăgdaş bir tarihçinin yapabileceği en iyi şey, Osman Tarihinin başlangıcının bir kara delikten ibaret olduğunu kabul etmek olacaktır. Bu deliği doldurmak yönündeki her girişim, yalnızca yaratılan masalların sayısını artırmakla sonuçlanacaktır”. Bkz. (Imber, 1993, s. 75; İmber, 1997, s. 77).

${ }^{4}$ Yaklaşık 1390'lı yıllara tarihlenen Ahmedî’nin Dasistan-i Tevarih-i Ali Osman’ı ile yine aynı süreçte yazıldığ kabul edilen ve günümüze ulaşmamış olsa da Aşıkpaşazâde'nin eserinde bazı kısımlarını kullandığını bildiğimiz Yahşi Fakih'in Menakıbnâmesi 14. yüzyıla ait nadir kaynaklardandır.

5 14. yüzyılda inşa edilen Osmanlı yapılarından, Orhan Gazi dönemine tarihlenen altı, I. Murad dönemine tarihlenen on bir ve Yıldırım Bayezid Dönemine tarihlenen yedi yapının kitabesi günümüze ulaşmıştır. 14. yüzyıl boyunca yaklaşık 430 yapı inşa edildiği dikkate alındığında, söz konusu kitabe sayılarının yapıların sayısına oranının \% 5 civarında olduğu anlaşılmaktadır. Erken Osmanlı Dönemi kitabeleri hakkında detaylı bilgi için bkz. (Tüfekçioğlu, 2001).

${ }^{6}$ 14. yüzyıldan günümüze ulaşan ve daha çok Bursa ve çevresindeki vakıfları temsil eden yaklaşık 15 vakfiye günümüze ulaşmıştır. Vakfiyeler hakkında bkz. (Öcalan vd. 2012; Gökbilgin, 1953). Mudurnu Yıldırım Hamamı Vakfiyesi için bkz. (Ayverdi, 1962; Tüfekçioğlu, 2001, s. 52-54)

${ }^{7}$ Erken dönem Osmanlı Sikkeleri hakkında bkz. (Uzunçarş1l1, 1945; s. 207-211; Aykut, 2002, s. 823-841; Tekin, 1999, s. 169- 179; Pere, 1968; Teoman, 2020, s. 399-434)

8 14. yüzyıla dair bilgi veren Bizans Kronikleri hakkında bkz. (Magoulias, 1975; Nikoloudis, 1996; Miller, 1975; Mclaughlin, 2017; Van Dieten, 1973)
} 
Menakıbnâmesi) kullanmaları sebebi ile birbirini tekrar eden anlatılardan ibarettir. ${ }^{9}$ Bazı bilgiler kendi içerisinde tutarsızdır ve kronolojide büyük boşluklar vardır. En önemlisi de aktarılan bilgilerin içeriği son derece sınırlıdır. 14. yüzyıl Osmanlı Beyliği'nin tarihine dair yazılanların büyük bir kısmının söz konusu olan kroniklerde yer alan bilgilerden ibaret olduğu göz önüne alındığında modern tarih araştırmalarındaki birbirinden kopuk, bütünlüğü olmayan bilgiler ile birçok hususta farklı görüş ve düşüncelerin varlığ 1 daha iyi anlaşılmaktadır. Bu ortamda alternatif alan çalışmalarının- ki bunlardan en önemlileri arkeolojik ve mimari bulgulardır- yeterli düzeyde olmayışı, var olan çalışmaların ise disiplinler arası ortak çalışma eksikliği sebebi ile göz ardı edilmesi önemli bir diğer sorundur.

$\mathrm{Bu}$ makalenin temel amacı da Osmanlı tarihi ile birlikte sosyo-kültürel ortama dair arkeolojik veriler ile dönem yapılarının sunduğu verilerin önemini vurgulamaktır. $\mathrm{Bu}$ amaçla Osmanlı Arkeolojisi'nin Osmanlı araştırmaları açısından önemini dönem tarihinin öne çıkan tarihsel olay-olguları örneklenerek tartışılmaya çalışılacaktır.

Osmanlı Beyliği'ne dair hala günceliğini koruyan en önemli problemlerden birisi hangi tarihte ve nerede kurulduğudur. Modern tarih literatüründe beyliğin 1299 yılında Karacahisar'da kurulduğu yönünde genel bir kabul olmakla birlikte, son dönemde farklı görüş ve öneriler bilim ortamında tartışılmaktadır. İlk Osmanlı tarih yazarlarının anlatılarında (Aşıkpaşazâde, Neşrî, Oruç Bey vb.) Karacahisar Kalesi'nin 1288 y1lında Osman Gazi tarafindan fethedildiği, kalenin alınmasının ardından - şehrin (kalenin) - evlerinin boş kaldığı ve Germiyan ile "başka yerlerden" çok sayıda insanın yerleştirildiği anlatılmaktadır. Bahsi geçen kaynaklarda ayrıca kiliselerin mescit ve camiye dönüştürüldüğü, pazar kurulduğu, ilk verginin burada kayda geçtiği ve Tursun Fakih tarafından ilk hutbenin de 1299 yılında Karacahisar Kalesi'nde okunduğu bilgileri yer almaktadır (Aş1kpaşazâde, 2003, s. 71-75; Neşrî, 1949, s. 111-113; Oruç Bey, 2009, s. 15-16). Neşrî’nin anlatımına göre Osman Gazi adına sikke yine bu süreçte basılmıştır (Neşrî, 1949, s. 111). Aynı tarihsel akışta kentin yönetimi Orhan Gazi'ye bırakılmış, Tursun Fakih kadı olarak atanmış, Gündüz Alp ise subaşı olarak görevlendirilmiştir (Neşrî, 1949, s. 99, 111). Bu verilerin tümü bağımsızlık sembolleri olup dolayısı ile Osmanlı tarihçileri genelde 1299 yılını ve Karacahisar'1 Osmanlı Beyliği'nin kuruluş tarihi ve yeri olarak kabul etmişlerdir. Buraya kadar Osmanlı'nın kuruluş tarihine dair herhangi bir problem yokmuş gibi görünmekle birlikte, söz konusu bilgilerin yer aldığ1 kroniklerdeki bilgilerin güvenirliğine dair çekinceler (İnalcık, 2000, s. 119-145; Imber, 2000, s. 271-300; Zachariadou, 2000, s. 341-396) bu tarih hususunda da baz1 bilim insanlarını tereddütte düşürmüş; H. İnalcık (2010) Osmanlı Devleti'nin 1299 yılında Karacahisar'da değil, 1302 yılında Yalova' da kurulduğunu ileri sürerek bilim camiası ile paylaşmıştır. 1299'a kaynaklık eden Osmanlı kroniklerindeki anlatılara dair çekincelerin yanısıra efsane ve gerçekleri birbirinden ayırmakta çekilen güçlügün ortaya çıkardığ tereddüt ile 1302 tarihine kaynaklık eden Pachimeres'in anlatılarında Osman Gazi'nin ilk kez çağdaş bir Bizans kaynağında isminin bildirilmesi, Osmanlı ile Bizans ordularının ilk defa büyük bir savaşta karşı karşıya gelmesi ve Osmanlı ordusunun bu savaşta büyük bir zafer kazanmasının o tarihte (1302) Osmanlı gücü ve gerçeğini yansıtmasının ötesinde doğrudan bir kuruluş tarihine kaynaklık edip edemeyeceği zaman içerisinde bilim insanları tarafından tartışılacaktır. Açık olan şu ki var olanların dışında yeni bir kaynağa ulaşılamadığı müddetçe Osmanlı'nın kuruluş tarihi ve yeri hususunda diğer birçok olguda olduğu gibi farklı görüş ve öneriler uzun yıllar güncelliğini koruyacakmış gibi görünmektedir.

Bu sorunu ya da belirsizliği ortadan kaldıracak veriler doğal olarak bilimsel çalışmalar neticesinde ortaya çıkacaktır. Bu kaynak belki keşfedilmemiş bir arşiv belgesi olacak, belki bir kitabe belki de arkeolojik çalışmalar sonucunda ortaya çıkarılacak bir sikke olacaktır. Ancak bu noktada alternatif çalışma alanlarının çeşitlenmesine ve disiplinler arası çalışmaların artırılmasına ihtiyaç olduğu açıktır.

\footnotetext{
${ }^{9}$ Yahşi Fakih Menakıbnâmesi hakkında bkz. (Ménage, 1963, s. 50-54; Zachariadou, 2000, s. 341-396).
} 
Bu alanlardan birisi de arkeolojik çalışmalardır. Osmanlı'nın kuruluş problemine çözüm üretmesi beklenen en önemli bilim alanlarından birisi nümizmatiktir. Öyle ki İstanbul Arkeoloji Müzeleri koleksiyonunda bulunan ve Osman Gazi'ye ait olduğu belirtilen sikkenin gerçek olup olmadığ hususunda farklı görüşler ileri sürülmüş, zaman içerisinde bahsi geçen sikkenin gerçek olduğu yönünde bir kabul oluşmuştur. Son dönemde ayrıca Doah National Museum ve bir özel koleksiyonda Osman Gazi'ye ait birer sikke olduğu yönünde araştırma sonuçları yayınlanmıştır ${ }^{10}$. Osman Gazi’ye ait olduğu belirtilen sikkelerde tarih bulunmaması kuruluş tarihi problemine yeni bir perspektif sunmasa da Osmanlı kroniklerinin genelinde Ertuğrul Gazi'nin babasının Süleyman Şah olduğu yönündeki bilginin aksine sikkede Gündüz Alp'in isminin kaydedilmiş olması, dönem araştırmalarına farklı bir veri sunarken, dönem kroniklerindeki bilgilere ihtiyatla yaklaşılması yönündeki tespitleri desteklemiş ve literatüre daha güvenilir bir bilgi kaymıştır. Tabi ki bu verilerin artması ve özellikle müze ve özel koleksiyonlarda bulunan, dolayısı ile nereden geldiği ve orijinalliği hususunda tereddüt oluşan sikkelerden ziyade arkeolojik çalışmalarda kültür tabakası ile birlikte in-situ olarak tespit edilecek yeni bulgular bu husustaki potansiyel çekincelerin giderilmesine katk1 sunacaktır.

Erken Osmanlı yerleşimlerinde ve başta Karacahisar, Bilecik, Yenişehir, Bursa, Yalova, İnegöl ve İznik gibi yerleşimlerde yapılacak kapsamlı arkeolojik kazılar bu yazıda odaklandığımız kuruluş dönemi başta olmak üzere Osmanlı'ya dair birçok olgu hakkında yeni veriler sunabilecektir. Ne yazık ki bahsi geçen verilere ulaşılma potansiyeli olan alanlarda yeteri kadar arkeolojik çalışma yapıldığını söylemek mümkün değil. Türkiye'de son yıllarda bu alanda bir ilgi gözlense de Osmanlı arkeolojisinin henüz başlangıç aşamasında bir alanı temsil ettiği gerçeği yadsinamaz.

Aşıkpaşazâde, Oruç ve Neşrî'nin anlatıları takip edildiğinde I. Murad dönemi sonuna kadar yaklaşık 122 yerleşimin Osmanlı fethi ve iskânına sahne olduğu anlaşılmaktadır. ${ }^{11}$ Ancak gerçek şu ki bahsi geçen yerleşimlerden çok azında arkeolojik çalışma gerçekleşmiştir. Kültür ve Turizm Bakanlığı verilerine göre Bakanlar Kurulu Onaylı sadece beş arkeolojik kazı doğrudan Osmanlı dokusuna odaklanmış olup, Osmanlı arkeolojisinin temsili olarak yorumlanabilecek niteliktedir. ${ }^{12}$ Başta kaynak azlığı olmak üzere diğer birçok sebebin yanısıra basettiğimiz arkeolojik çalışmalardaki azlık sebebi ile Osmanlı'nın Beylik dönemindeki pek çok önemli yerleşim yerinin tarihi ve kentsel dokusunun temel bileşenleri hakkında tatmin edici verilere hâlâ sahip değiliz. Örneğin Yenişehir diğer Osmanlı kentlerinden farklı olarak antik ve Bizans geçmişi olmayan ve doğrudan Osmanlılar tarafindan yeni kurulan bir yerleşim olması açısından son derece önemli bir kenttir. Kentte Osman Gazi tarafından yaptırıldığı belirtilen saray (Ayverdi, 1966, s. 14-15) kentin Osmanlı Beyliği'nin bir dönem idari merkezi olduğuna işaret etmektedir. Ancak bugüne kadar bu saraya dair ne bir tasvir ne bir gravür ne bir eski fotoğraf hiçbir veri yayınlanmamıştır. İlk Osmanlı Sarayı'nın ne mimarisini ne de diğer olgularını hayal bile edemediğimiz gibi bu yönde her hangi bir çıkış noktamız bulunmamaktadır. ${ }^{13}$ Sonrasında Bursa, Dimetoka, Gelibolu ve Edirne'de Osmanlı sultanları tarafindan kullanılan saraylar olduğu yönünde tarihi kaynaklarda veriler olmasına karşın, ne yazık ki bu saraylar hakkında bildiklerimiz de son derece sınırlıdır. Belki de

\footnotetext{
${ }^{10}$ Osman Gazi'ye ait sikke-sikkeler hususunda detaylı bilgi için bkz. (Artuk, 1980, s. 27-33; Paksoy, 2014, s. 443-456; Yilmaz, 2019, s. 81-120, Teoman, 2020, s. 403-405).

${ }^{11}$ Bahsedilen veriler, Aşıkpaşazâde, Neşrî ve Oruçbey tarihinde adı geçen küçük ve büyük ölçekli yerleşim yerlerinin yaklaşık değerleridir. Ancak bahsi geçen kroniklerde bu sayı farklıdır. Örneğin Tevarih-i Ali Osman'da 122'de, Kitab-1 Cihannüma'da 148, Oruç Bey tarihinde ise 97 yerleşim adı geçmektedir (Aşıkpaşazâde, 2003; Neşrî, 1949; Oruç Bey, 2009).

12 İznik Çini Fırınları Kazısı, Denizli Kale-i Tavas (Tabae) Kazısı, Edirne Yeni Saray Kazısı, Kırklareli Fatih Demir Dökümhanesi Kazısı, Eskişehir Karacahisar Kalesi Kazısı. Bu veriler Kültür ve Turizm Bakanlığı tarafından desteklenen kararnameli uzun süreli kazıları içermektedir. Bkz. (kulturvarlıkları.gov.tr., 2021). Arkeoloji Müzeleri tarafından yürütülen kurtarma kazıları bu değerlendirmeye dahil edilmemiştir.

${ }^{13}$ Yenişehir'deki Osmanlı Sarayı'nın tespitine yönelik bazı çalışmalar hakkında medyada haberler yer almasına rağmen bu çalışmaların detaylarına ve varsa bilimsel sonuçlarına ilişkin bilgilere ulaşılamamıştır. Bkz. (milliyet.com.tr., 2021).
} 
bahsi geçen saraylardan hakkında tarihi kaynaklarda en fazla bahsedileni olan Bursa Saray1 hakkındaki bilgilerimiz dahi seyyahların geç dönemdeki kısa tasvirleri ve saraya dair genel bir perspektif sunmaktan uzak birkaç gravür ile sınırlıdır. ${ }^{14}$

Erken Osmanlı tarihçilerini hala meşgul eden konulardan birisi Osmanlı Devleti’nin birçok davranış biçimine yön veren "Gaza" anlayışıdır. Bu noktada hâlâ araştırmacıların farklı yaklaşımlar ile tartıştı̆̆ı ve güncelliğini koruyan soru: Gaza yağmacı akın mıdır ? yoksa P. Wittek başta olmak üzere bazı araştırmacıların vurguladığ 1 gibi Gaza "İslam dinini korumak veya yaymak amacıyla Müslüman olmayanlara karşı yapılan bir kutsal savaş" mıdır ? ( Wittek, 2012; Lowry, 2010, s. 35104; Kafadar, 2010, s. 70-86; Emecen, 2012, s. 115-126; Lindner, 2015, s. 407-428; Jennings, 2015, s. 429-442). Bu makalenin konusu bahsi geçen sorunsalın tartışılmasından ziyade, gaza ve gazilik tartışmalarının en önemli kaynaklarından birisinin bir kitabede yer alan bilgiler olduğuna dikkat çekmektir. Bursa'da günümüze ulaşmayan bir yapının (Orhan Mescidi), bugün Şehadet Camisi'nin doğu kapısı üzerinde yer alan 1337 tarihli kitabesinin Ahmedî’nin İskendernâmesi ile birlikte çok sayıda yayına konu olmuş Osmanlı'da gaza anlayışına zemin hazırlayan bir içeriğe sahip olması, araştırma ve kazılar sonucunda bulunması muhtemel kitabelerin birçok bilinmeyene 1şık tutma ya da yeni çıkarımlara kaynaklık etme potansiyeline iyi bir örnek teşkil etmektedir. ${ }^{15}$ Ankara'daki Alaaddin Cami'sindeki onarım kitabesinin (Tüfekçioğlu, 2001, s. 32) 2. Osmanlı padişahı olan Orhan Gazi'nin vefatını 1358, 1359, 1360 gibi farklı tarihler ile aktaran Osmanlı kroniklerindeki bilgilerin (Aşıkpaşazâde, 2003, 111; Neşrî, 1949, s. 187) aksine 1362 y1lında Orhan Gazi 'nin iktidarda/yönetimde olduğunu ortaya koyması dönem kitabelerini önemini ortaya koyan bir diğer özel örnektir. ${ }^{16}$ Benzer şekilde günümüze ulaşmayan ancak kitabesi İznik Arkeoloji Müzesi'nde bulunan İznik Hacı Hamza Türbesi'nin kitabesinde "Hacı Ali" isminde bir mimar adının bildirilmesi Osmanlı mimarlık tarihi açısından başka bir dönem belgesinde karşımıza çıkmayan son derece özel ve benzersiz bir bilgi kaynağı olarak ön plana çıkmaktadır (Tüfekçioğlu, 2001, s. 22-24)

14. Yüzyıl boyunca Osmanlı kentlerinde yaklaşık 430 yapı inşa edildiği anlaşılmaktadır. Ne yazıkki bu yapılardan sadece 24'ünün kitabesinin günümüze ulaşmıştır. (Ayverdi, 1966, Y1lmazyaşar, 2017, s. 28). Kitabeler özelindeki bu istatistik döneme dair bilimsel manada içinde bulunduğumuz çıkmazın bir başka dönem belge türündeki yansımasını sunmaktadır. Ne yazık ki, bugün bildiğimiz 14. yüzyıl kitabelerinden sadece bir tanesi kazı çalışması ile ortaya çıkarılmıştır (Aslanapa, 1964-65, s. 23, Tüfekçioğlu, 2001, s. 20). İznik Orhan Gazi imareti kazılarında bulunan bu kitabe yapının tarihi, banisi ve İznik kentinin fetih sürecine dair sunduğu bilgilerin yanı sıra hacıların Osmanlı'nın ilk dönemlerinden itibaren Osmanlı toplumundaki varlıkları ve imaretlerin bu kişilere emanet edildiği yönündeki çıkarımlara kaynaklık etmesi bakımından yine altı çizilmesi gereken bir belge olarak ön plana çıkmaktadır.

$\mathrm{Bu}$ noktada döneme dair hala tartış1an iki önemli kent ve söz konusu kentlerin fetih tarihlerine odaklanmakta fayda vardır. Erken Osmanlı döneminin iki önemli başkenti olan Bursa ve Edirne'nin fethedildiği tarihlerin hala tartışılıyor olması aslında önceki satırlarda sıklıkla

\footnotetext{
${ }^{14}$ Tarihi kaynaklarda Bursa Sarayı ile ilgili ilk referanslar İbn-i Batuta ve Gregory Palamas'ın tasvirlerinde karşımıza çıkmaktadır. (İbn Batuta, 2004, s. 430-31; Philippidis - Braat, 1979, s. 146). Gregory Palamas'a göre Orhan Gazi 1355 yılında çoğunlukla Bursa'daki sarayında bulunmakta olup, yazları ise Bursa'ya yaklaşık 2 gün mesafedeki bir köyde geçirmektedir (Philippidis - Braat, 1979, s. 146). Bursa Müzesi'nin 1980'lerde yürüttüğü kazı çalışmaları sırasında bulunan bazı kalıntılar, bir Osmanlı sarayından çok, alanın Bizans geçmişine işaret etmiş (Kütük, 1986) yine son yıllarda sarayın olduğu düşünülen alandaki jeoradar taramaları bazı veriler sunmuştur (Çağaptay, 2012, s. 179-190; Çağaptay, 2011, s. 179-190) Son dönemde Bursa Sarayı'na odaklanan bir araştırma süreci ve bu sürece dair gerçekleşen sempozyum, bahsettiğimiz sorunsala yönelik heyecan verici bilimsel çabalar olarak son derece anlamlı olmakla birlikte bu tür girişimlerin artması ve bilimsel olarak alanda somut sonuçlara ulaşması gerekmektedir (Yurteser Yılmaz (Ed.), 2021).

${ }^{15} 1337$ kitabesi hakkında bkz. (Ayverdi, 1966, s. 59; Tüfekçioğlu, 2001, s. 22-24; Wittek, 2012, s. 53; Lowry, 2010 , s. $39)$.

${ }^{16}$ Kitabedeki bilgiden yola çıkarak Orhan Gazi’nin saltanat yıllarına dair çıkarım için bkz. (İnalcık, 2009a, s. 56).
} 
vurguladığımız kaynak eksikliğinin bir sonucudur. Bahsi geçen iki kentin de Osmanlı Devleti'ne başkentlik yapmış olması sebebi ile nispeten diğer kentlere göre kaynakların daha fazla veri sunması gerekirken hâlâ fetih tarihlerinin dahi tartışılıyor olması, diğer kentler açısından özellikle 14. yüzyıl bağlamında bilimsel ortama umutsuz bir tablo sunmaktadır. Osmanlı kronikleri Bursa'nın fethini 1322 ve 1326 gibi farklı tarihlerle aktarmaktadırlar (Neşrî, 1995, s. 135; Oruç Bey, 2009, s. 17; Aşıkpaşazâde, 2003, s. 86). Literatürde ağırlıklı olarak 1326 yılı kabul edilse de 1324 yılını öneren çalışmalar da bulunmaktadır (Yılmazyaşar, 2017, s. 93). Aslında tarihi kayıtlardaki birkaç yıllık tutarsızlık kayda değer görünmeyebilir ancak bu tarihlerin tarihsel olayları anlamamızda ve tarihlememizde domino etkisi vardır. Örneğin bazı kronik yazarlarının bildirdiğine göre Bursa'nın fethi Orhan Gazi'nin tahta çıktığı yıla ve ayrıca Murad'ın doğum tarihine rastlamaktadır (Sadettin Efendi, 1999, s. 50, 53); dolayıs1 ile söz konusu tarih hususundaki netlik birçok önemli olguya dair tarihlendirme hususunda da daha kesin yargılara ulaşılmasına olanak sağlayacaktır. Bursa'da Orhan Gazi döneminde 29 yapı inşa edildiği bilinmekle birlikte sadece 5 yap1 günümüze ulaşmıştır (Ayverdi, 1957, s. 117; 1966, s. 18-19; Y1lmazyaşar, 2003, s. 201). Kentin fethedilmesinin hemen ardından inşa edilen bugün günümüze ulaşamayan yapıların bir kısmının yaklaşık yerleri bilinmesine karşın söz konusu yapılara dair herhangi bir kazı çalışması gerçekleşmemiştir. Bahsi geçen yapılara ait olası bir kitabenin Bursa'nın fethi ile birlikte diğer sorunsallara dair yönelik veriler sunması mümkündür. Bu bağlamda döneme dair yazılı kaynakların araştırmacılar tarafından bütünü ile kullanıldığı göz önüne alındığında başta arkeolojik çalışmalar olmak üzere yeni araştırma alanlarının sunacağı verilere odaklanmak yerinde olacaktır.

Döneme dair önemli bir diğer veri / bilgi kaynağı da Osmanlı mimari eserleridir. Düzgün ve doğru okunduğunda, mimari eserler / kalıntılar dönem uzmanları için birer belge niteliğinde içerik sunmaktadır. Dolayısıyla bu makalede, mimari verilere kültürel etkileşimler ve sosyal yapılar bağlamında da yaklaşılacaktır.

14. yüzyılda Osmanlı Beyliği, Osman Gazi, Orhan Gazi, I. Murad ve Yıldırım Bayezid olmak üzere dört farklı sultan tarafindan yönetilmiştir. 1230'lardan itibaren Sögüt ve çevresinde varlık gösteren 1299-1300 yıllarından itibaren bölgedeki özellikle Bizans tekfurları açısından bir tehdit olarak algılanacak güç haline evrilen Osmanlılar, özellikle Bursa (1324/1326) ve İznik'in (1331) fethi sonrasında Batı Anadolu'daki hâkimiyetini sağlamlaştırmıştır (Yılmazyaşar, 2017, s. 29,30). Osmanlı Beyliği 1362 yılının sonunda yani Orhan Gazi devri sona erdiğinde kurulduğu coğrafyanın çok ötesinde Rumeli ve kısmen Balkanlara kadar uzanan 75.000 km'lik bir alanı hâkimiyeti altına almıştır (Pitcher, 2001, s. 70). Beylik toprakları Yıldırım Bayezid döneminde Avrupa'da 227.000 Asya'da ise 470.000 km'ye ulaşmıştır (Pitcher, 2001, s. 70). Oldukça hızlı gelişen söz konusu fetihler ile genişleyen Osmanlı Beyliği ele geçirilen topraklara komşu çok sayıda farklı uygarlık ve söz konusu uygarlıkların temsil ettiği kültür ile doğrudan ya da dolaylı olarak temasta bulunmuştur.

$\mathrm{Ne}$ yazık ki, Osmanlı mimarisinin oluşumunda etkili olan mimari gelenekler üzerine kapsamlı çalışmaların gerçekleştirildiğini söylemek mümkün değildir. Bu durumun temel nedeni, mimarlık ve sanat tarihi çalışmalarının ağırlıklı olarak hâlâ belgeleyici bir anlayış üzerine kurulu olmasıdır. Belgeyici yaklaşımın tercih edildiği çalışma sonuçları literatüre bir çok yeni bilgi kazandırıyor olsa da, ortaya çıkan verilerin değerlendirilmesinde tarihsel, coğrafi, siyasi, askeri, ticari ve sosyo-kültürel etkilerin analitik ve bütüncül bir perspektif ile ele alınmasındaki noksanlıklar kültürel etkileşim, sosyal olgular gibi bazı önemli çıktıların gözden kaçmasına sebep olmaktadır. Mimarinin kaçınılmaz olarak toplumdaki birçok dinamiğin etkisi ile şekillendiği ve bu dinamiklerin bir anlamda yansımaları - somutlaşmış temsilleri olduğu göz önüne alındığında bu açıdan yaklaşılan araştırma sonuçlarının söz konusu döneme dair çok kıymetli veriler sunacağı aşikardır.

$\mathrm{Bu}$ sorunsalı birkaç örnek ile izah etmek gerekirse, Orhan Gazi döneminden itibaren Yıldırım Bayezid dönemine kadar Osmanlı yapılarında ana yapı malzemesi taş ve tuğla olup, tercih 
edilen teknik ise bu iki malzemenin birlikte kullanılması ile oluşan almaşık tekniktir. Bu tespit şüphesiz bugüne kadar birçok araştırmacı tarafindan gözlemlenmiş ve belgelenmiştir (Batur, 1970, s. 135-227; Şener, 1997, s. 193-249). Ancak bu noktada tartışılması gereken, 14. yüzyılın 3. çeyreğine kadar inşa edilen yapılarda taş ve tuğla tercih edilirken, yüzyılın sonlarına doğru neden kesme taş malzemenin ağırlıklı olarak Osmanlı mimarisinde ana inşa malzemesi olarak ön plana çıktığ 1 ve almaşık teknik uygulamasının geçici bir süre ile de olsa neden terkedildiğidir. Gerçek şu ki, Osmanlı mimarisinde 14. yüzyılın sonlarına kadar ağırlıklı olarak almaşık duvar tekniği kullanılmış olup, testere dişi tuğla saçaklar, damla dizileri, kör kemerler, çift kemer uygulamaları, bazı yapıların dış cephelerindeki kalp ve rozet motifleri rastgele/her hangi bir etkenden bağımsız uygulamalar değildir. Bununla birlikte I. Murad döneminin sonunda Osmanlı mimarisinde yapıya özel tasarlanmış ilk sütun başlıklarının İznik Nilüfer Hatun İmareti ile birlikte karşımıza çıkışı; özgün taş süsleme örneklerinin ilk olarak 1380'lere ait yapılarda uygulanmasi; Yıldırım Bayezid döneminde İznik Yeşil Cami sonrasında taş süslemelerin mimarinin vazgeçilmez unsuru haline gelmesi ve yine duvar çinilerinin mimarideki tercihinin yüzyılın sonundan itibaren yaygınlaşması da tesadüfi uygulamalar değildir.

$\mathrm{Bu}$ bağlamda amacımız önceki satırlarda paylaşılan gözlemlerin arkasındaki nedenleri tartışmak olmasa da döneme ilişkin belgeleri yok denecek kadar az olan 14. yüzyıla ait yapılarda kullanılan malzeme ve teknik detayların dahi bir çok çıkarıma kaynaklık etme potansiyeli olduğu aşikardır. Dolayısı ile döneme dair sosyo-kültürel, siyasi ve ekonomik şartlar ile birlikte ele alınarak değerlendirilmesinin gerekliliği göz ardı edilmemelidir. Çünkü ele aldığımız örneklem bağlamında mimarideki değişim, Osmanlı Beyliği'nin ulaştığ1 coğrafi sınırlar, karşılaştı̆̆ kültürler, mimari geleneği ve mirası, bünyesine dahil ettiği mimar ve zanaatkârların temsili ve ekonomik koşullar gibi bir dizi kavramla yakından ilişkilidir.

14. yüzyılın ilk yarısında gerçekleştirilen uygulamalarda Bizans mimari geleneğinin etkisi ve I. Murad dönemi sonunda mimaride ve özellikle malzeme teknik ve bezeme detaylarında yaşanan keskin dönüşümler coğrafya, siyasi değişimler, ekonomik koşullar, sosyo-kültürel çevre, ilişkiler, akrabalık, stratejiler ve hoşgörü gibi olgu ve kavramlar bağlamılyla incelenmelidir. Mimari unsurlar bir anlamda tarihi verilerin maddi kanıtıdır ve söz konusu mimari verilerin dili ile tarihi kaynaklardaki veriler birlikte değerlendirildiğinde döneme dair daha kapsamlı bir perspektif ile karşılaşmak mümkündür.

Osmanlı kroniklerinde sıkça bahsedilen Osman Gazi ile Harmankaya Tekfur'u Köse Mihal'in arasındaki dostluk (Aş1kpaşazâde, 2003, s. 64); Bizans İmparatoru Kantekuzenos'un Orhan Gazi'nin kayınpederi olması; Osman Gazi'nin Hıristiyanlarla olan iyi ilişkisinin sebebi sorulduğunda verdiği cevap ${ }^{17}$, Osman Gazi'nin yaylalara giderken bazı eşyalarını Bilecik Tekfuruna emanet etmesi ve dönüşte peynir, kaymak, kilim vs. gibi hediyeler getirmesi gibi bir çok anlatı (Aşıkpaşazâde, 2003, s. 66) aynı coğrafyada yaşayan iki farklı kültürün ortak yaşam pratiğinin kroniklerdeki yansımalarıdır. Osman Gazi dönemini yansıtan söz konusu anlatıların Orhan Gazi dönemindeki temsili Gregory Palamas'tır. Palamas'a göre İznik'te Hıristiyanlar ile Türkler yanyana yardımlaşarak yaşamaktadırlar (Philippidis - Braat, 1979, s.136; Demircan, 1993, s. 43). Orhan Gazi ve I. Murad dönemlerinde Osmanlı Beyliği'nin mimarisinde karşılaşılan almaşık teknik başta olmak üzere cephe düzen ve süsleme unsurları ile Geç Bizans döneminde sıklıkla karşılaşılan mimari unsurlar arasındaki benzerliğin sebepleri tartışılırken ${ }^{18}$ önceki satırlarda sınırlı sayıda alıntıyla örneklenen Osmanlı ve Bizans kültürleri arasındaki ilişkinin varlığı ile I. Murad dönemi sonunda bir çok Bizans kentini ele geçirmiş, bölgenin hakim gücü haline gelmiş olan

\footnotetext{
17 "Osman Gazi ......... Bilecik kafiderine pek fazla hürmet ediyordu. "Bu Bilecik kafiderinin senin yaninda neden bu kadar hürmeti var, niçin bunlara değer veriyorsun?" diye sorduklarında, "Komşularımızdır, biz bu yere geldiğimiz zaman acınacak durumda idik, bunlar bizi hoş tuttular. Şimdi bize yakışan bunlara saygı duyup iyilik etmektir" cevabını verdi" Bkz. (Aşıkpaşazâde, 2003, s. 66)

${ }^{18}$ Bu hususta bkz. (Ersen, 1986; Ousterhout, 1995, s. 48-62)
} 
Osmanlı'ya dahil olarak toplumun bir parçası haline gelmiş yerel unsurların varlığını ve bu hususlardaki tarihsel kayıtların gözardı edilmemesi gerekir.

1380 sonrasında Osmanlı mimarisindeki malzeme teknik tercihlerindeki keskin değişimin sebepleri de aynı bağlamda tarihsel veriler ile birlikte değerlendirilmelidir. 1380'lerde Germiyanoğlu Beyliği topraklarının büyük bölümünün Osmanlı topraklarına katılması, aynı süreçte Hamidoğulları'nın Osmanlı'ya dahiliyeti, Yıldırım Bayezid'ın Germiyanoğlu Beyi'nin kızı ile Karamanoğlu Mehmed Bey'in I. Murad'ın kızı Nefise Melek Hatun ile evlenmesi , 1389 sonrası Batı Anadolu Beylikleri'nin büyük bölümünün Osmanlı Beyliği tarafından ele geçirilmesi gibi tarihsel olaylar (Aș1kpaşazâde, 2003, s. 117; Sadettin Efendi, 1999, s. 152,153) ile Osmanlı Mimarisi'ndeki bahsi geçen değişim arasında mutlak bir ilişki olmalıdır. 1380 sonrası başlayan bu değişimin nedenleri tartışılırken, 1389 y1lında Kosova'ya kadar ilerleyen Osmanlı Devleti'nin gerek fetihler ile elde ettiği ganimetler gerekse ticaret ile sağlanan gelirlerinin sonucunda ekonomik olarak oldukça güçlü bir duruma ulaşması ve bu husustaki tarihsel veriler de değerlendirmeye dahil edilmelidir.

Erken Osmanlı tarihi ve kültürü hakkında bilinmeyenler ve tartışmalı konulara ilişkin "yeni" çıkarımlar ve değerlendirmeler için Osmanlı arkeolojisi ve mimari araştırmalarının önemi hususunda son y1llarda önemli bir farkındalık oluşmuş olsa da, arkeoloji ve sanat tarihi araştırma sonuçlarının tarih araştırmalarında, tarihi kaynakların ve araştırma sonuçlarının da arkeoloji ve sanat tarihi araştırmalarında henüz yeterli düzeyde atıf aldığını söylemek mümkün değildir. Belki de bu durumun temel nedeni hâlâ disiplinler arasında yürütülmesi gereken ortak bilimsel araștırmalarının - projelerin henüz istenilen düzeyde olmayıșıdır. Bu hususta bir diğer önemli eksiklik ise Türkiye'de yürütülen arkeolojik araştırmaların sayısal dağılımına ilişkindir.

Önceki bölümde seçilmiş bazı örneklerle açıklandığı gibi, Osmanlı arkeolojisi ve mimarisi üzerine yapılan - yapılacak kapsamlı araştırmalar erken Osmanlı döneminin keşfedilmemiş kısımlarına önemli ölçüde ışık tutma potansiyeline sahip olmakla birlikte, özelde Osmanlı genelde ise Türk-İslam arkeolojisini temsil eden kazı çalışmalarının ihtiyaç duyulan - olması gereken düzeyde olduğunu söylemek mümkün değildir. Kültür ve Turizm Bakanlığı'nın verilerine göre, 2006-2020 yılları arasında Bakanlar Kurulu kararlı (2019 y1lı itibari ile Cumhurbaşkanı Kararlı) yı1lık ortalama 145 arkeolojik kazı çalışması yürütülmüştür. ${ }^{19}$ Bu kazı alanlarının 2006 yılında yalnızca \%7,27'si (2006: 110/8), 2020 yılında ise \%9,35'i (2020: 139/14) Türk-İslam dönemlerine odaklı arkeolojik çalışma alanlarıdır. 2020 yılı itibari ile Türkiye'de uzun süreli ya da kısa süreli Türk-İslam arkeolojisini temsil eden toplamda 60 (altmış) kazı çalışması gerçekleştirilmiş olup bu kazılardan 17'si hâlen uzun süreli kazı statüsünde sürdürülmektedir (Ağırgöl, 2020, s. 76-77, 324329).

${ }^{19}$ Bkz. Tablo 1. (kulturvarlıkları.gov.tr., 2021) 
Tablo 1: Türkiye'deki Bakanlar Kurulu Kararlı Kazılar / Türk - İslam Dönemi Kazıları (2006 - 2020) (kulturvarlıkları.gov.tr., 2021)

\begin{tabular}{|c|c|c|c|c|}
\hline YIL & $\begin{array}{l}\text { CUMHURBASSKANLIĞI/ } \\
\text { BAKANLAR KURULU KARARLI } \\
\text { TÜRK BïLIM HAYETLERINCE } \\
\text { YÜRÜTÜLEN KAZILAR }\end{array}$ & $\begin{array}{l}\text { CUMHURBASSKANLIĞI / } \\
\text { BAKANLAR KURULU KARARLI } \\
\text { YABANCI BİLIM HAYETLERINCE } \\
\text { YÜRUUTTÜLEN KAZILAR }\end{array}$ & TOPLAM & $\begin{array}{c}\text { CUMHURBAŞKANLIĞI / } \\
\text { BAKANLAR KURULUU KARARLI } \\
\text { TÜRK İSLAM DÖNEMI } \\
\text { KAZILARI }\end{array}$ \\
\hline 2006 & 71 & 39 & 110 & 8 \\
\hline 2007 & 85 & 44 & 129 & 13 \\
\hline 2008 & 92 & 43 & 135 & 13 \\
\hline 2009 & 98 & 48 & 146 & 13 \\
\hline 2010 & 111 & 40 & 151 & 17 \\
\hline 2011 & 123 & 43 & 166 & 20 \\
\hline 2012 & 116 & 39 & 155 & 19 \\
\hline 2013 & 109 & 34 & 143 & 17 \\
\hline 2014 & 117 & 36 & 153 & 16 \\
\hline 2015 & 120 & 36 & 156 & 19 \\
\hline 2016 & 112 & 29 & 141 & 17 \\
\hline 2017 & 118 & 32 & 150 & 19 \\
\hline 2018 & 122 & 31 & 153 & 17 \\
\hline 2019 & 124 & 32 & 156 & 11 \\
\hline 2020 & 118 & 21 & 139 & 14 \\
\hline TOPLAM & 1636 & 547 & 2183 & 233 \\
\hline
\end{tabular}

Erken Osmanlı dönemi ile doğrudan ilişkili arkeolojik çalışma alanı sayısı ise sadece 3'tür: İznik Çini Fırınları Kazısı, Eskişehir Karacahisar Kalesi Kazısı ve Edirne Sarayı Kazısı ${ }^{20}$. Bu istatistiklere ilgili kentlerin Arkeoloji Müzeleri tarafından yürütülen kazılar (İznik Orhan İmareti, Bilecik Orhan İmareti ve Eski Bilecik Kenti, Bursa Orhan Hamamı vb.) eklendiğinde dahi Erken Osmanlı dönemine odaklanan arkeolojik kazı çalışmalarının kararnameli kazılar içerisindeki temsiliyeti yaklaşık \%3'tür. ${ }^{21}$

Türkiye'de Paleolitik dönemden Bizans dönemine kadar hüküm sürmüş kültür ve uygarlıklara ev sahipliği yapmış alan - yerleşimlerde uzun yıllardır birçoğu kesintisiz bir süreklilikte ve birbirini tamamlar nitelikte sonuçlara ulaşılan çok sayıda arkeolojik çalışma yürütülmektedir. $\mathrm{Bu}$ veriler arkeolojik çalışmalarının niceliği açısından bir problem olmadığını ancak Türk-İslam arkeolojisinin Türkiye'de henüz istenilen seviyeye ulaşamadığını ortaya koymaktadır.

$\mathrm{Bu}$ durumun istenilen seviyeye ulaşamayışının temel nedenlerinden biri Türkiye'deki üniversitelerde Türk-İslam arkeolojisi ile ilgilenen uzman sayısının son derece az olmasıdır. Hal böyle olunca alan akademik ilgiyi çekmekte yetersiz kalmaktadır. İzmir Katip Çelebi Üniversitesinde Türk İslam Arkeolojisi adlı bir bölümün (ikcu.edu.tr., 2021), Çanakkale Onsekiz Mart Üniversitesinde ise Osmanlı Arkeolojisi ad1 altında bir Lisanüstü programın (ebs.comu.edu.tr., 2021) hayata geçirilmesi akademik alanda Türk İslam ve Osmanlı arkeolojisinin bağımsız bir disiplin olarak yerleşmesi yönünde radikal ve son derece önemli adımlar olmakla birlikte, bahsettiğimiz tüm bu oluşumların sonuçlarının kaliteli ve kabul gören bir zemine oturması için zamana ihtiyacı olduğu açıktır.

Yerleşimlerin birçoğunun Osmanlı döneminden itibaren günümüze kadar kesintisiz olarak kullanıldığı göz önüne alındığında geniş kapsamlı arkeolojik kazı yapılmasının başta kamulaştırma

\footnotetext{
${ }^{20}$ Bahsi geçen kazılar hakkında detaylı bilgi için bkz. (Aslanapa, vd. 1988; Altınsapan vd, 2010, s. 1-17; Altınsapan vd, 2015, s. 621-633; Altınsapan vd., 2018; Demirsar Arlı, 2011, s. 61-77; Özer, 2014).

${ }^{21}$ Türkiye'deki Türk-İslam arkeolojisine dair kapsamlı analiz ve değerlendirmeler için bkz. (Ağırgöl, 2020)
} 
sorunu olmak üzere birçok sebepten dolayı mümkün olmadığı aşikârdır. Ancak bu sebepler önceki satırlarda aktarılan Türk-İslam arkeolojisine dair istatistiklerin doğrudan izahı değildir. Öyle ki gerek Selçuklu ve Beylikler gerekse Osmanlı dönemine ait olup üzerine modern bir doku oluşmayan, arkeolojik kazılar ile ortaya çıkarılabilecek çok sayıda yerleşim ve yapı bulunmaktadır. Örneğin bugün Çanakkale'nin Ayvacık İlçesi'ne bağlı bir köy olan Tuzla'da I. Murad döneminde inşa edilmiş cami, medrese ve hamamdan oluşan küçük bir külliye bulunmaktadır (Ayverdi, 1966, s. 355-358; Yenişehirlioğlu, 1987, s. 5-14; Yılmazyaşar, 2017, s. 340-350). Bu külliyenin mescidi günümüze sağlam ve kullanılabilir durumda ulaşmış, hamamın sadece küçük bir kısmı kalmış, medrese ise tamamen toprak altındadır. I. Murad döneminde farklı yerleşimlerde yedi adet medrese inşa edildiği bilinmekle birlikte, bu eserlerden sadece Bursa'da I. Murad İmareti'nin üst katında yer alan medrese günümüze ulaşabilmiştir. Bu bağlamda Tuzla'daki medresede gerçekleştirilecek bir arkeolojik kazı, Osmanlı mimarisine ait yeni bir yapının ortaya çıkarılmasının yanı sıra, erken Osmanlı medrese mimarisi hakkında son derece önemli veriler sunacak, aynı zamanda bölge turizmi için kıymetli bir kazanım oluşacaktır. Eski Manyas ve Kara Biga gibi hala modern yerleşim alanı dışında kalan ve Osmanlı yerleşim arkeolojisi açısından önemli olabilecek çok sayıda alan bulunmaktadır. Bu noktada Osmanlı özelinden bakılacak olursa, Osmanlı döneminden günümüze ulaşmış ve arkeolojik çalışmalar gerçekleştirilebilecek alan-yapıların tespitine yönelik bir belgeleme çalışması yapılması son derece faydalı olacaktır.

Arkeolojik çalışmalarda vurguladığımız eksiklik teorik ve literatüre dayalı araştırmalarda da karşımıza çıkmaktadır. 2000'li yıllarda başlayan Osmanlı arkeolojisine yönelik ilgi ile eş zamanlı bu hususta son derece kıymetli bazı çalışmalar yayınlanmış olmasına karşın bu yayınların sayısının yeterli olduğunu söylemek mümkün değildir. ${ }^{22}$ Son zamanlarda Doğu Avrupa'da (özellikle Balkanlar, Yunanistan ve Bulgaristan'da) her geçen gün artan ilgi ile Osmanlı Arkeolojisine yönelik gerçekleştirilen çalışmalar ile yine aynı süreçte Ortadoğu ülkelerindeki Osmanlı mirasının aydınlatılmasına yönelik kazılar bahsi geçen bölgeler için lokal önemli sonuçlar ortaya koymuş olsa da $^{23}$ Türkiye ve yurtdışındaki Osmanlı arkeolojisine yönelik çalışmaların bütüncül bir değerlendirmesi bugüne kadar yapılamamıştır.

Sonuç olarak mimarlık ve sanat tarihi ile arkeolojik kazı çalışmaları sonucunda ortaya çıkabilecek potansiyel veriler yazılı belgelerin yok denecek kadar az olduğu Erken Osmanlı dönemine dair son derece kıymetli çıkarım ve bilgilere kaynaklık ederek bilimsel çalışmalara farklı bir perspektif kazandırabilecektir. Bu bağlamda öncelikle Türk-İslam arkeolojisi ile ilgili alan çalışmaların nicelik olarak artırılmasına ihtiyaç olduğu açıktır. Türkiye'deki üniversitelerde Türkİslam arkeolojisini temsil eden bölüm, anabilim dalı, enstitü ve araştırma merkezlerinin artırılması akademik çalışmalara zemin oluşturmasının yanısıra alana dair uzman yetiştirilmesini sağlayacaktır. Türkiye ve yurtdışında bugüne kadar gerçekleştirilmiş özelde Osmanlı arkeolojisi daha genel bağlamda Türk-İslam arkeolojisini temsil eden kazı çalışmalarına dair bir envanter çalışmasının henüz gerçekleştirilmemiş olması önemli bir eksikliktir. Bu yöndeki bir çalışma çıktısı ve kazı sonuçlarının karşılaştırmalı olarak değerlendirilmesini içeren yayınlar bilim ortamına önemli bir katkılar sunacaktır. Disiplinler arası çalışmaların azlığı bu çalışmada ele aldığımız 14. yüzyıl başta olmak üzere farklı uygarlık dönemlerine yönelik bilimsel çalışmalardaki önemli eksikliklerden birisidir. Her biri farklı uzmanlık ve birikim gerektiren tarih, sanat tarihi ve arkeoloji bilimleri arasındaki disiplinler arası çalışmaların artması, verilere ulaşma ve multidisipliner perspektifte bütüncül değerlendirmelere olanak sağlayayarak bilimsel sonuçların kalitesini artıracaktır.

\footnotetext{
22 Bkz. (Arık, 1999, s. 43-59; Baram ve Carroll, 2000; Yenişehirlioğlu, 2005, s. 245-265; Dikkaya, 2015; Körpe, Baskıda; Ürer, 2018; Ağırgöl, 2020).

${ }^{23}$ Bkz. (Baram ve Carroll, 2000, 2004; Baram, 2002, Kovács ve Tomka, 2003, s. 405-413; Bintliff, 2015, s. 347-369; Petersen, 2017, s. 23-48; Peker vd., 2017, s. 93-157).
} 


\section{Kaynakça}

Ağırgöl, M. (2020). Koruma kuramları ve mevzuat kapsamında Türkiye'de yapılan Türk İslam dönemi kazılarına ilişkin değerlendirme, [Yayınlanmamış yüksek lisans tezi], Ondokuz Mayıs Üniversitesi, Lisansüstü Eğitim Enstitüsü.

Altınsapan vd., (2010). Karacahisar kalesi 2009 yılı temizlik ve kazı çalışmaları. XIV. Ortaçağ ve Türk Dönemi Kazılarl ve Sanat Tarihi Araştırmaları Sempozyumu. Konya, 1-17.

Altınsapan, E. \& Palalı, M. (2018). Osmanlı beyliğinin kurulduğu yer, Eskişehir Karacahisar Kalesi kazı buluntuları (2011-2014), Doğukütüphanesi Yayınları.

Altınsapan, E., Demirel Gökalp Z., Yılmazyaşar, H. \& Gerengi, A. (2015). 2011-2014 kazıları 1şı̆̆ında Eskişehir Karacahisar kalesi, Akademik Sosyal Araştırmalar Dergisi, 3, (10), 621633

Arık, M. O. (1999). Türk kültürüne yönelik arkeolojik çalışmalar ve sorunları, Uluslararası Dördüncü Türk Kültür Kongresi, Ankara (1999), 43-59.

Artuk, İ. (1980). Osmanlı Beyliğinin kurucusu Osman Bey’e ait sikke, I. Uluslararası Türkiye'nin Sosyal ve Ekonomik Tarihi (1071- 1920) Kongresi., (Ed.) O. Okyar, H. İnalc1k) Ankara, $27-33$

Aslanapa, A., Yetkin, Ş. \& Altun, A. (1988). İznik çini firınları kazısı II. Dönem 1981-1988.

Aslanapa, O. (1964-65). İznik’te Sultan Orhan İmâret Camii kazısı. İstanbul Üniversitesi Edebiyat Fakültesi Sanat Tarihi Yıllı ̆̆, I, 16-31.

Âşık Paşazade (2003). Osmanoğulları'nın tarihi, (Çev.) Kemal Yavuz, M. A. Yekta Saraç, K Kitaplığ1.

Atsız, (1992). Aşıkpaşaoğlu tarihi. Kültür Bakanlığı Yayınları.

Aykut, N. Ş. (2002). Osmanlı sikkeleri. Türkler, c. 10, 823-841, Ankara.

Ayverdi, E. H. (1957). Orhan Gazi devrinde mimari. Ankara Üniversitesi Illahiyat Fakültesi Yıllık Araştırmalar Dergisi, I, 115-197.

Ayverdi, E. H. (1962). Mudurnu'da Yıldırım Bayezid manzumesi ve taş vakfiye. Vakıflar Dergisi, $\mathrm{V}, 79-92$.

Ayverdi, E. H. (1966). Osmanlı mimarisinin ilk devri. İstanbul: Fetih Cemiyeti Yayınları.

Baram, U. \& Carrol, L. (Ed.) (2000). A Historical archaeology of The Ottoman Empire - Breaking New Ground, Kluwer Academic Publishers.

Baram, U. (2002). The development of ottoman archaeology in Israel: An overview and prospects. Historical Archaeology, 36, 12-29.

Baram, U. \& Carrol, L. (Ed.) (2004). Osmanlı Arkeolojisi, Kitap Yayınevi.

Batur, A. (1970). Osmanlı camilerinde almaşı duvar üzerine. Anadolu Sanatı Araştırmaları, 2, $135-227$.

Bintliff, J. (2015). The archaeology of Ottoman to early modern Greece. Recent Developments in the Archaeology of Greece, Leuven, Pharos Supplement, 347-369.

Çağaptay, S. (2011). Depremler, arkeoloji ve Bursa'nın erken Osmanlı döneminin anatomisi, Uluslararası Katılımlı XV. Ortaçağ ve Türk Dönemi Kazıları ve Sanat Tarihi Araştırmaları Sempozyuти Bildirileri, (Ed.) Z. D. Gökalp vd. Eskişehir, 179-190. 
Çağaptay, S. (2014). Archaeology report: Results of the Tophane area GPR surveys, Bursa, Turkey. Dumbarton Oaks Papers, 68 (113), 145-179.

Demircan, H. (1993). Orhan Gazi ve Gregory Palamas, [Yayınlanmamış yüksek lisans tezi], Ankara Üniversitesi Sosyal Bilimler Enstitüsü.

Demirsar Arl1, B. (2011). An Evaluation of Iznik excavation results between 1981-2009, Arab Historical Review for Ottoman Studies, Tunis, 61-77.

Dikkaya, F. (2015). The historical archaeology of the early ottomans: A new perspective on arguments about the foundation of the Ottoman empire, [Yayınlanmamış doktora tezi], İhsan Doğramac1 Bilkent Üniversitesi, Tarih Bölümü.

Emecen, F. (2012). Gazâya dair XIV. yüzyıl kaynakları arasında bir gezinti, Illk Osmanlılar ve Batı Anadolu Beylikler Dünyası, Timaş Yayınları, 115-126.

Ersen, A. (1986). Erken Osmanlı mimarisinde cephe biçim düzenleri ve Bizans etkilerinin niteliği. İstanbul: İTÜ Mimarlık Fakültesi Yayınları.

Gökbilgin, T. (1953). Murad I. tesisleri ve Bursa İmareti vakfiyesi. Türkiyat Mecmuası, X, 217234.

Imber, C. (1993). The legend of Osman Gazi, The Ottoman Emirate (1300-1389), (Ed.) Elizabeth A. Zachariadou,. Rethymnon, 67-76.

Imber, C. (1997). Osman Gazi efsanesi, Osmanl Beyliği (1300-1389). (Ed.) Elizabeth A. Zachariadou, (Çev. G. Çağalı Güven, İ. Yerguz, T. Altınova), Tarih Vakfı Yurt Yayınları, 68-77.

Imber, C (2000). İlk dönem Osmanlı tarihinde düstur ve düzmece, (Çev.) F. Acun, Söğ̈̈t'ten İstanbul'a: Osmanlı Devleti'nin Kuruluşu Üzerine Tartışmalar (Der.) O. Özel, M. Öz., 271300.

İbn Batuta. (2004). İbn Battuta seyahatnamesi I-II. Yapı Kredi Yayınları / Kazım Taşkent Klasik Yapitlar Dizisi.

İnalcık, H. (2000). Aşıkpaşazâde tarihi nasıl okunmalı ?, Söğüt'ten İstanbul'a: Osmanlı Devleti'nin Kuruluşu Üzerine Tartışmalar, (Der.) O. Özel, M. Öz., 119-145.

İnalcık, H. (2009) Devleti Aliye (Osmanlı İmparatorluğu üzerine araştırmalar-I). Türkiye İş Bankası Kültür Yayınları.

İnalcık, H. (2010). Osmanlı tarihini yeniden yazmak: Kuruluş. İstanbul: Hayy Kitap.

Jennings, R. C. (2015). Gazi tezi üzerine düşünceler, Söğüt'ten İstanbul'a: Osmanl Devletinin Kuruluşu Üzerine Tartışmalar, İmge Kitabevi, 429-442.

Kafadar, C. (2010). İki cihan aresinde, Birleşik Yayınevi.

Kovács, G. \& Tomka, G. (2003) The Archaelogy of the Otoman Period, XII. Chapter: The Middle Ages and the Post-Medieval Period, Hungarian Archeology at the Turn on the Millennium, (Der. J. Laszlovszky), Budapest., 405-413.

Körpe, R. (Baskıda) Tarih araştırmalarında yeni bir metot: Osmanlı arkeolojisi, Uluslararası Prof. Dr. Halil İnalcık Tarih ve Tarihçilik Sempozyumu, (Ankara, 10 Nisan- 13 Mayıs 2017, Baskıda)

Kütük, S. (1986). Bizans galerisi kazısı, (Yayınlanmamış Rapor), Bursa Kültür Varlıklarını Koruma Bölge Kurulu Arşivi. 
Lindner, R. P. (2015). İlk dönem Osmanlı tarihinde itici güç ve meşruiyet, Söğ̈̈t'ten İstanbul'a: Osmanlı Devletinin Kuruluşu Üzerine Tartışmalar, İmge Kitabevi, 407-428.

Lowry, H. (2010). Erken dönem Osmanlı Devleti’nin yapısı. Bilgi Üniversitesi Yayınları.

Magoulias, Harry J. (1975). Decline and fall of Byzantium to the Ottoman Turks, Detroit: Wayne State University Press.

Mclaughlin, B. S. (2017) An annotated translation of Emperor John VI Kantakouzenos, History, Book III, [MPhil/PhD theses in progress], Hellenic Institute, Royal Holloway, University of London, UK.

Ménage, V. L. (1963). The Menaqib of Yakhshi Faqih, Bulletin of the School of Oriental and African Studies 26, 50-54.

Miller, T. S. (1975). The History of John Cantacuzenus (Book IV): Text, Translation and Commentary, The Catholic University of America.

Neşrî (1949). Kitab-ı Cihanüma 1. (Haz.) F. R. Unat \& M. A. Köymen. Türk Tarih Kurumu Yayınları.

Nikoloudis, N. (1996). A Translation and commentary of the demonstrations of histories, Athens.

Oruç Bey (2009). Osmanlı tarihi. (Sadeleştiren) N. Öztürk. Çamlıca Yayınları.

Ousterhout, R. (1995). Ethnic identity and cultural appropriation in Early Ottoman architecture. Muqarnas, 12, 48-62.

Öcalan, H. B. vd. (2013). Bursa vakfiyeleri I., Bursa Kültür A. Ş.

Özer, M. (2014). Edirne Sarayı (Saray-ı Cedid-i Âmire) kısa bir değerlendirme, Bahçeşehir Üniversitesi Yayınları.

Paksoy, İ. G. (2014). Osman Gazi'nin şimdiye kadar yayımlanmış tek gümüş sikkesi üzerine düşünceler, I. Uluslararası Anadolu Para Tarihi ve Numismatik Kongresi, Bildiriler (Ed.) K. Dörtlük, O. Tekin \& R. B. Seyhan, İstanbul, 443-456.

Peker, A. U., vd. (2017) Zigetvar Kanunî Sultan Süleyman Türbe-Palankası'nda Araştırma ve Arkeolojik Çalışmalar 2015-2017, Uluslararası Ortaçağ ve Türk Dönemi Kazıları ve Sanat Tarihi Araştırmaları Sempozyumu, Antalya, Türkiye, 26 - 27 Ekim 2017, 93-157

Pere, N. (1968). Osmanlılarda madeni paralar, İstanbul: Yapı ve Kredi Yayınları.

Petersen, A. (2017). Under the Yoke: The Archaeology of the Ottoman Period in Bulgaria. Journal of Islamic Archaeology, 4(1), 23-48.

Philippidis-Braat, A. (1979). La captivité de Palamas chez les Turcs: Dossier et commentaire, Travaux et Mémories 7, 109-221

Pitcher, D. E. (2001). Osmanlı İmparatorluğu'nun tarihsel coğrafyası, (Çev.) B. Tırnakçı. Yapı Kredi Yayınları.

Sadettin Efendi. (1999). Tacüt Tevarih I., (Haz.) İ. Parmaksızoğlu. Kültür Bakanlığı Yayınları.

Şener, Y. S. (1997). XIV. yüzyıl Bursa yapılarında erken Osmanlı duvar örgüsü. Türk Etnografya Dergisi, 20, 193-249.

Tekin, O. (1999). Osmanlı İmparatorluğu'nda para, Osmanlı Ansiklopedisi, c. 3, 169- 179.

Teoman, B. (2020). Erken Dönem Osmanlı sikkeleri (1299-1453), Fetih Öncesi Osmanlı Sanatı ve Mimarisi, (Ed.). Y. Özbek \& A. Budak. LiteraTürk Yayınları. 399-434.

Tüfekçioğlu, A. (2001). Erken Dönem Osmanlı mimarisinde yazı. Kültür Bakanlığı Yayınları. 
Uzunçarşı11, İ. H. (1945). Gazi Orhan Bey'in hükümdar olduğu tarih ve ilk sikkesi,, TTK Belleten, IX, 207-211.

Ürer, H. (2018). Türk İslam arkeolojisi ve terminolojisi, Ege Yayınları.

Van Dieten, J. A. (1973) Nikephoros Gregoras, Rhomäische Geschichte: Historia Rhomaike. Stuttgart.

Wittek, P. (2012). The Rise of the Ottoman Empire, studies in the history of Turkey, ThirteenthFifteenth Centuries, (Ed.) Colin Heywood, London.

Yenişehirlioğlu, F. (1987). Tuzla'da Hüdavendigar Camii. Rölöve ve Restorasyon Dergisi, 6, 5-14.

Yenişehirlioğlu, F. (2005). L'archeologie historique de l'Empire ottoman: Bilan et perspectives, Turcica, 37., 245-265.

Yılmaz, H. (2019). Osman Gazi'nin 700/1300-1301'de Yenişehir'de bastırdığı üçüncü sikkesi, Vakanüvis, 81-120.

Yılmazyaşar, H. (2003). Orhan Gazi döneminde İznik kenti ve mimarisi, [Yayınlanmamış yüksek lisans tezi], Hacettepe Üniversitesi Sosyal Bilimler Enstitüsü.

Yılmazyaşar, H. (2017). Bursa'dan Kosova'ya: Hüdavendigar (I. Murad) dönemi Osmanlı mimarisi, [Yayınlanmamış doktora tezi], Anadolu Üniversitesi Sosyal Bilimler Enstitüsü.

Yurteser Yılmaz, S. T. (Ed.),( 2021). Osmanl Devleti'nin yönetim merkezi Bursa Bey Sarayl, Bursa Büyükşsehir Belediyesi Kitaplığı.

Zachariadou, E. A. (2000). İlk Osmanlılara dair tarih ve efsaneler. (Der. M. Öz ve O. Özel) Söğ̈̈t'ten Ístanbul'a, İmge Kitabevi, 341-396.

Zachariadou, E. A. (2000). İlk Osmanlılara dair tarih ve efsaneler. İstanbul'a: Osmanl Devleti'nin Kuruluşu Üzerine Tartışmalar (Der.) O. Özel, M. Öz., 341-396.

\section{İnternet Kaynakları}

Kazı ve Yüzey Araştırmaları (2021, Aralık 23). kulturvarlıkları.gov.tr.

http://www.kulturvarliklari.gov.tr/TR,44150/kazi-ve-yuzey-arastirmalari-faaliyetleri.html

Yenişehir Sarayı (2021, Aralık 23). milliyet.com.tr.

http://www.milliyet.com.tr/osmanli-nin-ilk-sarayi-gunyuzune-gundem-1881839/

İKÜ Türk İslam Arkeolojisi (2021, Aralık 23). ikcu.edu.tr.

https://turk-islamarkeolojisi.ikcu.edu.tr

ÇOMÜ Osmanlı Arkeolojisi (2021, Aralık 23). comu.edu.tr.

https://ubys.comu.edu.tr/AIS/OutcomeBasedLearning/Home/Index?id=6815\&culture= 